Adıyaman Üniversitesi Sağlık Bilimleri Dergisi, 2020;6(2):207-215

doi:10.30569.adiyamansaglik.709435

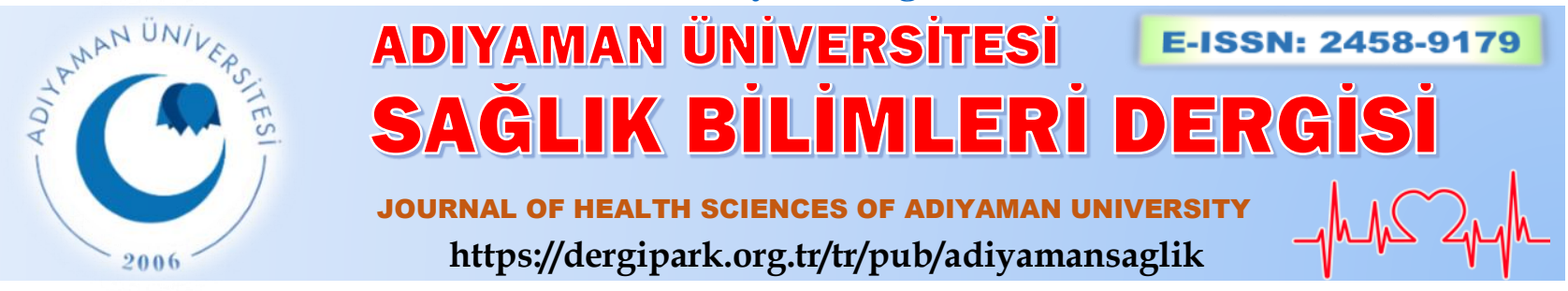

Özgün Araştırma/Research Article

\title{
Hemşirelerin fiziksel aktivite düzeyleri ile yaşam kaliteleri arasındaki ilişsinin incelenmesi: tanımlayıcı bir araştırma
}

\section{Investigation of the relationship between physical activity level and quality of life of nurses: a descriptive study}

\author{
Fikret KILINÇ $@$ @ \\ ${ }^{1}$ Hasan Kalyoncu Üniversitesi Sağlık Bilimleri Enstitüsü, 27100, Gaziantep-Türkiye
}

Atıf gösterme/Cite this article as: Kılınç F, Tosun N. Hemşirelerin fiziksel aktivite düzeyleri ile yaşam kaliteleri arasındaki ilişkinin incelenmesi: tanımlayıcı bir araştırma. ADYÜ Sağllk Bilimleri Derg. 2020;6(2):207-215. doi:10.30569.adiyamansaglik.709435

Öz

Amaç: Bu çalışmanın amacı, bir eğitim ve araştırma hastanesinde görev yapan hemşirelerin fiziksel aktivite düzeyleri ile yaşam kaliteleri arasındaki ilişkiyi araştırmaktır.

Gereç ve Yöntem: $\mathrm{Bu}$ araştırma, bir üniversite hastanesinde çalışan 442 hemşire ile yürütülmüştür. Hemşirelerin bazı sosyo-demografik özellikleri kayıt edilmiş, fiziksel aktivite düzeyleri Uluslararası Fiziksel Aktivite Anketi Kısa Formu, yaşam kalitesi düzeyleri ise SF-36 Yaşam Kalitesi Ölçeği kullanılarak belirlenmiştir.

Bulgular: Hemşirelerin sadece \%19,9'unun yeterli fiziksel aktivite düzeyine sahip olduğu belirlenmiştir. Hemşirelerin yaşı ilerledikçe ve beden kitle indeksi arttıkça fiziksel fonksiyon yaşam kalitesi düşmektedir. Erkekler kadınlara göre, kronik hastalığı olmayanlar olanlara göre daha yüksek düzeyde yaşam kalitesine sahiptir.

Sonuç: Yeterli düzeyde fiziksel aktivite hemşirelerin yaşam kalitesini olumlu şekilde etkilemektedir.

Anahtar Kelimeler: Hemşireler; Fiziksel egzersiz; Yaşam kalitesi.

\begin{abstract}
Aim: The aim of this study is to investigate the association between the physical activity levels and quality of life of the nurses working in an education and research hospital.

Materials and Methods: Thisstudywas conducted with 442 nurses working in a university hospital. Sociodemographic characteristics of nurses were recorded, physical activity levels were determined using the International Physical Activity Questionnaire Short Form, and quality of life levels were determined using SF-36 Quality of Life Scale

Results: Only $19.9 \%$ of the nurses had sufficient physical activity level. As the age of the nurses and the body mass index increases, physical functional domain of the quality of life decreases. Men and those without chronic disease have higher level of quality of lifethan women andthose with chronic disease.

Conclusion: Adequate physical activity affects the quality of life of nurses positively.

Keywords: Nurses; Physical exercise; Quality of life.
\end{abstract}

Yazışma Adresi/Address for Correspondence: Fikret KILINÇ, Hasan Kalyoncu Üniversitesi Sağlık Bilimleri Enstitüsü, 27100, Gaziantep-Türkiye, E-mail: fikretkhb@gmail.com

Geliş Tarihi/Received:26.03.2020 Kabul Tarihi/Accepted:19.05.2020

Yayım Tarihi/Published online:30.08.2020

Bu eser, Creative Commons Atıf-GayriTicari 4.0 Uluslararası Lisansı ile lisanslanmıştır. Telif Hakk1 @ 2020 Adıyaman Üniversitesi Rektörlüğü 


\section{Giriş}

İnsanların yaşamları boyunca sağlıklı olabilmeleri, yani sağlıklı yaşayabilmeleri için yeterli düzeyde fiziksel aktiviteye sahip olmaları gereklidir. Yetersiz fiziksel aktivite kronik hastalıkların oluşmasına ve erken ölümlere zemin hazırlayabilmektedir. ${ }^{1,2}$ Geçmişten günümüze kronik hastalıkların görülme sıklığı artmaktadır. Bilhassa erken yaşlarda görülen kronik hastalıklar kişiyi ve yakın çevresini fiziksel, duygusal ve ekonomik olarak etkileyerek kişinin yaşam kalitesine olumsuz yönde etki yapmaktadır. ${ }^{3,4}$ Fiziksel olarak aktif olanlarda kardiyovasküler hastalık, iskemik inme, Tip 2 Diyabet, kolon kanseri, osteoporoz, depresyon ve düşme nedenli yaralanma gelişme riski daha düşüktür. ${ }^{5}$

Fiziksel aktivitenin düzenli yapılması obeziteyi ve obezite ile ilişkili hastalıkların görülme sıklığını azaltmakta, beden sağlı̆̆ının yanında ruh sağlığı üzerinde de olumlu etkiler oluşturmaktadır. ${ }^{6-8}$ Sağlığın korunması ve geliştirilmesi için, yetişkin bireylerin, haftada beş gün en az yarım saat orta yoğunlukta aerobik fiziksel aktivite veya haftada üç gün en az 20 dakika kuvvetli yoğunlukta aerobik aktivite yapması önerilmektedir., ${ }^{9,10}$ Fiziksel aktivitenin sağlık ve yaşam kalitesi üzerinde pozitif etkileri vardir. ${ }^{3}$ Bireyin fiziksel, psikolojik ve ruhsal durumlarını kapsayan yaşam kalitesi; ait olduğu sosyo-kültürel sistem dâhilinde, bireyin yaşamındaki olayları kavramaları ve yorumlamaları olarak tanımlanmaktadır. ${ }^{11}$ Hemşireler, sağlık bakım ve tedavi hizmetinde görev alan sağlik iş gücünün önemli bir bölümünü oluşturmaktadır. ${ }^{12}$ Hemşirelik mesleğinin doğası gereği, hemşireler her zaman iş kazası, hastalık riski ve yoğun çalışma temposu altında çalışmak gibi farklı stres faktörleriyle karşı karşıya kalırlar. $\mathrm{Bu}$ stres faktörleri, fiziksel ve zihinsel güçlerini azaltarak ve günlük işlevlerini bozarak sağlıkla ilgili yaşam kalitelerini kademeli olarak azaltabilmektedir. ${ }^{13,14} \quad$ Literatürde hemşirelerin yaşam kalitesinin fiziksel aktivite seviyeleri ile ilişkili belirli sayıda çalışma mevcuttur.
Yukarıda anlatılanlar 1şı̆̆ında, bu çalışmanın amacı, bir üniversitenin eğitim araştırma hastanesinde görev yapan hemşirelerin bazı sosyo-demografik özellikleri ve fiziksel aktivite düzeylerinin yaşam kaliteleri ile ilişkisini araştırmaktır.

\section{Gereç ve Yöntem}

\section{Araştırmanın tipi}

Tanımlayıcı tipte gözlemsel araştırma tasarımına sahip bu araştırmada, HaziranEkim 2017 tarihleri arasında bir üniversitenin eğitim ve araştırma hastanesinde görev yapan hemşirelerin fiziksel aktiviteleri ve yaşam kaliteleri arasındaki ilişki araştırılmıştır. $\mathrm{Bu}$ araştırma Helsinki Bildirgesi ilkelerine uygun olarak yürütülmüş, makalenin yazımında Strengthening the Reporting of Observational studies in Epidemiology (STROBE) kontrol listesi kullanılmıştır. ${ }^{15}$

\section{Araştırmanın evreni ve örneklem}

Araştırmanın evrenini, hastanede görev yapan 534 hemşire oluşturmaktadır. Bunların 448'i kadın ve 86'sı erkektir. Çalışma öncesi örneklem seçilmemiş olup tüm evrene ulaşılmaya çalışılmıştır.

Çalışmanın tek dâhil edilme kriteri, çalışma süresince hemşire olarak çalışıyor olmaktır. Çalışma süresince; doğum izni, kurum dışında görevlendirme gibi çeşitli nedenlerle hastanede aktif olarak çalışmayan, nöbet izni gibi nedenlerle ulaşılamayan ve çalışmaya katılmaya onam vermeyen hemşireler çalışma dişında bırakılmıştır. Çalışmaya katılmayı kabul eden $442(\% 82,8)$ hemşirenin tamamı anketi tamamlamıştır (Şekil 1).

\section{Veri toplama araçları}

Veriler çalışmaya katılmayı kabul eden hemşirelere yüz yüze görüşme tekniğgi ile uygulanan, yaş, cinsiyet, öğrenim düzeyi, medeni durum, boy-kilo, kronik hastalık ve sürekli kullandığı ilaç bilgileri içeren tanıtıcı bilgi formu, Uluslararas1 Fiziksel Aktivite Anketi Kısa Formu ve SF-36 Yaşam Kalitesi Ölçeği kullanılarak toplanmıştır. 
Hastanedeki hemşire $(\mathrm{n}=534)$

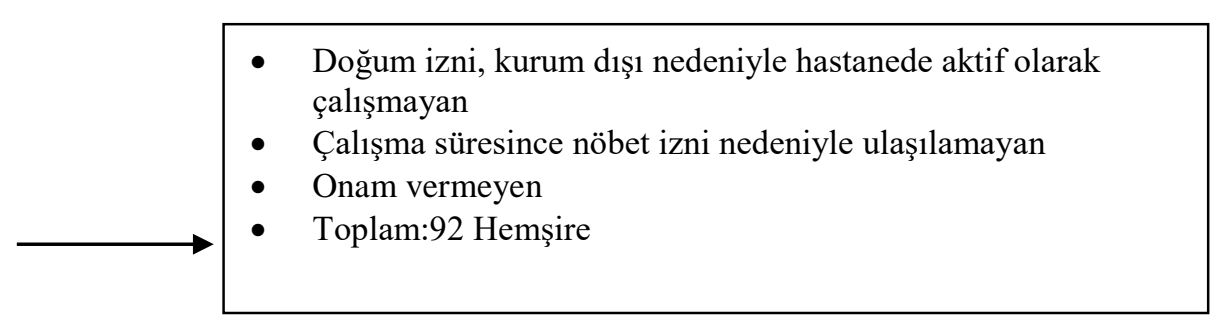

Çalışmaya katılan $(\mathrm{n}=442)$

Anketi tamamlamayan $(\mathrm{n}=0)$

Analize dâhil edilen $(n=442)$

Şekil 1. Çalışmanın akış şeması

Boy ve vücut ağırlığı kullanılarak beden kitle indeksi (BKİ) hesaplanmıştır. BKİ 18,5 $\mathrm{kg} / \mathrm{m}^{2}$ nin altında ise zayıf, $18,5-24,9 \mathrm{~kg} / \mathrm{m}^{2}$ arasinda ise normal kilolu, $25-29,9 \mathrm{~kg} / \mathrm{m}^{2}$ arasında ise fazla kilolu, $30 \mathrm{~kg} / \mathrm{m}^{2}$ ve üzerinde ise obez olarak sınıflandırılmıştır. ${ }^{16}$

Uluslararas1

Fiziksel

Aktivite Değerlendirme Anketi K1sa Formu (International Physical Activity Questionnaire Short Form, IPAQ Short Form); 15-65 yaş aralığındaki bireylerin fiziksel aktivite düzeylerini belirlemek amacıyla Craig ve arkadaşları tarafından 2003 yılında geliştirilen $^{17}$ ve Türkçe geçerlilik ve güvenilirlik çalışması Öztürk tarafından 2005 yılında yapılan ${ }^{18}$ ölçeğin, dakika, gün ve metabolik eşdeğeri (metabolic equivalent, METdeğeri) çarpılarak "MET-dakika/hafta" olarak bir puan elde edilmektedir. Fiziksel aktivite düzeyleri; fiziksel olarak aktif olmayan (<600 MET- dk/hafta), fiziksel aktivite düzeyi düşük (600-3000 MET$\mathrm{dk} /$ hafta) ve fiziksel aktivite düzeyi yeterli olan (sağlık açısından yararlı olan) (>3000 MET-dk/hafta) Sinıflandirılmaktadır. ${ }^{17,18}$

Katılımcıların yaşam kalitesini değerlendirmek amaciyla Ware ve Sherbourne tarafindan 1992 yllinda geliştirilen $^{19}$ ve Türkçe geçerlilik ve güvenilirlik çalışması Koçyiğit ve arkadaşları tarafindan 1999 yılında yapılan ${ }^{20}$, SF-36 Yaşam Kalitesi Ölçeği kullanılmıştır. Ölçek; fiziksel fonksiyonellik (FF), fiziksel fonksiyona bağl1 rol kisitlılığı (FFRK), bedensel ağrı (BA), genel sağlık (GS), mental sağlık (MS), emosyonel fonksiyona bağlı rol kisitlılığı (EFRK), sosyal fonksiyonellik (SF) ve canlılık/enerji (C/E) alt boyutlarından oluşmaktadır. Alt boyutlar için puan dağılımı 0-100 arasında değişmekle beraber, puan arttıkça yaşam kalitesi düzeyi yükselmektedir.

\section{Verilerin analizi}

Veriler SPSS versiyon 21 istatistik yazılımı (IBM Corp. in Armonk, NY) kullanılarak 
analiz edilmiştir. Sayısal değişkenlerin dağılımı Kolmogorov-Smirnov testi kullanılarak değerlendirilmiştir. Normal dağılıma uyan sayısal değişkenlerin tanımlayıcı istatistikleri ortalama \pm standart sapma ile, kategorik değişkenlerin ise frekans (n) ve yüzde (\%) ile gösterilmiştir. Normal dağılım gösterdiği tespit edilen değişkenlerinin gruplar arası karşılaştırması için İki Ortalama Arasındaki Farkın Önemlilik Testi ( $\mathrm{t}$ test) ve ANOVA testi kullanılmıştır. İstatistiksel anlamlılık sınırı 0,05 olarak kabul edilmiştir.

\section{Araştırmanın etik boyutu}

Araştırma için ilgili üniversitenin etik kurulundan etik kurul izni (Etik Kurul No: 2017-05, Tarih: 02/05/2017), ilgili ilin Kamu Hastaneleri Birliği Genel Sekreterliğinden idari izin alınmıştır. Çalışmaya katılmaya aday tüm hemşireler sözel olarak bilgilendirilmiş ve gönüllülük esasına göre katılmayı kabul edenlerden yazılı onam formu alınmıştır. Çalışma, tasarımından raporlama aşamasına kadar Helsinki Bildirgesi ilkelerine uygun olarak yürütülmüştür.

\section{Bulgular}

Çalışmaya katılan hemşirelerin yaş ortalamas1 33,10 $\pm 6,44$ olup, \%40,5'i 20-30 yaş, \%46,4'ü 31-40 yaş ve \%13,1'i 41 yaş ve üzeri grupta yer almaktadır. Katılımciların \%86,2'si kadın, \%13,8'i erkek, \%67,2'si evli ve \%32,8'i bekârdır. Lise mezunu hemşirelerin oranı\%17,0 olup, \%61,8'i lisans mezunu ve \%21,2'si yüksek lisans ve üzeri mezunudur. Hemşirelerin Beden Kitle İndeksi (BKI)'ne göre \%2,3'ünün zayıf, \%57,7'sinin normal, \%32,1'inin kilolu, \%7,9'unun obez olduğu belirlenmiştir. Hemşirelerin $\% 16,1$ 'inde kronik hastalık mevcut olduğu ve \%14,9'unun sürekli ilaç kullandığı saptanmış olup, \%32,1'inin fiziksel olarak aktif olmadığ $1, \quad \% 48,0$ 'inin fiziksel aktivite düzeyinin düşük ve \%19,9'unun fiziksel aktivite düzeyinin yeterli olduğu belirlenmiştir (Tablo 1).

Tablo 1. Katılımcıların sosyodemografik özellikleri, sağlık özellikleri ve fiziksel aktivite düzeyleri.

\begin{tabular}{|c|c|}
\hline Özellik (n=442) & \\
\hline Yaş (yıl), Ortalama \pm SS (Minimum-Maksimum) & $33,10 \pm 6,44(20,0-55,0)$ \\
\hline 30 yaş ve altı, n $(\%)$ & $179(40,5)$ \\
\hline $31-40$ yaş arası, $\mathrm{n}(\%)$ & $205(46,4)$ \\
\hline 40 yaş üzeri, $\mathrm{n}(\%)$ & $58(13,1)$ \\
\hline \multicolumn{2}{|l|}{ Cinsiyet, $\mathrm{n}(\%)$} \\
\hline Kadın & $381(86,2)$ \\
\hline Erkek & $61(13,8)$ \\
\hline \multicolumn{2}{|l|}{ Öğrenim durumu, n (\%) } \\
\hline Lise mezunu & $75(17,0)$ \\
\hline Lisans mezunu & $273(61,8)$ \\
\hline Yüksek lisans ve üzeri & $94(21,2)$ \\
\hline \multicolumn{2}{|l|}{ Medeni durum, $\mathrm{n}(\%)$} \\
\hline Bekâr & $145(32,8)$ \\
\hline Evli & $297(67,2)$ \\
\hline \multicolumn{2}{|l|}{ Beden kitle indeksi, n (\%) } \\
\hline Zayıf & $10(2,3)$ \\
\hline Normal kilolu & $255(57,7)$ \\
\hline Fazla kilolu & $142(32,1)$ \\
\hline Obez & $35(7,9)$ \\
\hline \multicolumn{2}{|l|}{ Kronik hastalık varlığı, n (\%) } \\
\hline Var & $71(16,1)$ \\
\hline Yok & $371(83,9)$ \\
\hline \multicolumn{2}{|l|}{ Sürekli ilaç kullanımı, n (\%) } \\
\hline Var & $66(14,9)$ \\
\hline Yok & $376(85,1)$ \\
\hline \multicolumn{2}{|l|}{ Fiziksel aktivite düzeyi, n (\%) } \\
\hline Fiziksel olarak aktif olmayan & $142(32,1)$ \\
\hline Fiziksel aktivite düzeyi düşük & $212(48,0)$ \\
\hline Fiziksel aktivite düzeyi yeterli & $88(19,9)$ \\
\hline
\end{tabular}


Katılımcıların yaşları ilerledikçe FF alt boyutuna ait yaşam kalitesi düzeyi istatistiksel olarak anlamlı şekilde düşmektedir $(p<0,001)$. Bununla birlikte, yaş gruplarına göre, ölçeğin diğer alt boyutlarından alınan puanlar açısından anlamlı bir fark saptanmamıştır. Erkekler FF, FFRK, BA, GS, MS, SF ve C/E alt boyutlarında geçerli olmak üzere, kadınlara göre daha yüksek yaşam kalitesine sahip iken (hepsi için $p<0,001$ ), yalnızca EFRK alt boyutundan alınan puan dağılımları erkekler ve kadınlar arasında benzer bulunmuştur. Katılımcıların öğrenim düzeyine göre ölçeğin tüm boyutlarından alınan yaşam kalitesi puan dağılımları istatistiksel olarak benzerdir. Bekârlar, FF, FFRK, BA, GS, SF ve C/E alt boyutlarında geçerli olmak üzere, evlilere göre daha yüksek yaşam kalitesine sahip iken (hepsi için $p<0,001)$, sadece MS ve EFRK alt boyutundan alınan puan dağılımları bekâr ve evliler arasında benzer bulunmuştur (Tablo 2). Hemşirelerin beden kitle indeksi arttıkça yaşam kalitesi ölçeğinin FF alt boyutundan aldıkları puanlar istatistiksel olarak azalmaktadır $(p<0,001)$. Ayrıca zayıf ve obez bireylerin BA alt boyutu açısından yaşam kalitesi düzeyleri istatistiksel olarak anlamlı şekilde düşüktür $(p<0,001)$. Diğer alt boyutlardan alınan puanlar beden kitle indeksi ile ilişkili bulunmamıştır. Kronik hastalığ olmayanlar, olanlara göre FF, FFRK, BA, GS ve $\mathrm{C} / \mathrm{E}$ alt boyutlarından daha yüksek puan almıştır (hepsi için $p<0,001$ ). Aynı durum sürekli ilaç kullanmayanlarda da geçerlidir (hepsi için $p<0,001$ ). Bu iki özellik için MS, EFRK ve SF alt boyutlarından alınan puan dağılımları benzer bulunmuştur (Tablo 3 ). Çalışmaya katılan hemşirelerin fiziksel aktivite düzeyleri arttıkça, FF, FFRK, BA, GS, MS, SF ve C/E alt boyutlarında geçerli olmak üzere, yaşam kalitesi düzeyi istatistiksel olarak artmaktadır (hepsi için $p<0,001)$. Sadece EFRK alt boyutundan alınan puan katılımcıların fiziksel aktivite düzeyleri ile istatistiksel olarak ilişkili bulunmamıştır (Tablo 4).

\section{Tartışma}

Dünya Sağlı Örgütü'nün $2010 \quad$ y1lı verilerine göre, tüm ülkelerde erişkinlerin \%23'ünün yeteri kadar fiziksel aktivite yapmadığı bildirilmiştir. $^{3}$ Genç erişkinlerde fiziksel aktivite düzeyinin araştırıldığı başka çalışmada ise, fiziksel aktivite düzeyinin düşük olduğu ve kadınlarda düzeyin daha düşük olduğu saptanmıştır. ${ }^{21}$ Hemşirelerin fiziksel aktivite seviyeleriyle ilgili yapılmış araştırmaların derlendiği bir çalışmada, bizim çalışmamızın bulgularına benzer şekilde, hemşirelerin genellikle düşük yoğunlukta fiziksel aktivite yaptığı bulunmuştur. ${ }^{22} \mathrm{Bu}$ bulguların nedenleri, hemşirelerin sağlık iş gücü içerisinde emek yoğun çalışması ve bireysel fiziksel aktiviteye ayracak zamanlarının olmaması olabilir.

Çalışmamızda hemşirelerin yaşı ilerledikçe FF yaşam kalitesi düştüğünü bulduk. Konuyla ilgili literatür incelendiğinde, hemşirelerin hizmet süreleri dolayısıyla yaşları artıkça fiziksel fonksiyonellik seviyelerinin daha düşük olduğu görülmüştür. ${ }^{23,24}$ Yaş ilerledikçe kronik hastalık görülme sıklığının artması ve yaşlanmanın insan vücudu üzerindeki yıpratıcı etkileri bu sonucun nedeni olabilir.

Hemşirelerde cinsiyete göre yaşam kalitesi alt boyutlarında farklılıklar olabilmektedir. Kadın hemşirelerin, özellikle fiziksel fonksiyonellik, genel sağlık ve mental sağlık alt boyutlarında erkeklerden daha düşük düzeyde yaşam kalitesine sahip olduğu gösterilmiştir. ${ }^{25,26}$ Hemşirelik dışındaki başka meslek gruplarında da benzeşen çalışmalar yapılmış, erkeklerin yaşam kalitelerinin kadınlardan daha yüksek olduğu gösterilmiştir. ${ }^{21,27,28}$ Benzer şekilde, bizim çalışmamızda da erkek hemşirelerin kadın hemşirelere göre birçok alt boyutta daha yüksek düzeyde yaşam kalitesine sahip olduğunu bulduk. Bunun nedeni, toplumsal cinsiyetin erkek ve kadına biçtiği rollerin çalışma yaşamında da etkisi olması olabilir.

Hemşirelerin medeni durumu ile yaşam kaliteleri arasındaki ilişkiyi farklı şekilde bildiren çalışmalar mevcuttur. ${ }^{25,26}$ Literatürde çoğunlukla evli kişilerin yaşam kalitesi düzeyinin bekârlardan daha yüksek olduğu; evliliğin kişiler arasındaki sosyal destek ihtiyacını karşıladığı finansal olarak bireyleri daha güçlü kıldığı yalnızlığın etkilerini azaltarak yaşam kalitesini yükselttiği belirtilmektedir. $^{29}$ 
Tablo 2. Katılımcıların sosyodemografik özelliklerine göre yaşam kalitesi düzeyleri.

\begin{tabular}{|c|c|c|c|c|c|c|c|c|}
\hline \multirow{2}{*}{ Özellik (n=442) } & \multicolumn{8}{|c|}{ SF-36 Yaşam Kalitesi Ölçeği Alt Boyut Puanları (Ortalama \pm SS) } \\
\hline & FF & FFRK & $\mathbf{B A}$ & GS & MS & EFRK & SF & $\mathbf{C} / \mathbf{E}$ \\
\hline \multicolumn{9}{|l|}{ Yaş } \\
\hline 30 yaş ve altı & $79,41 \pm 17,22$ & $70,94 \pm 38,14$ & $63,24 \pm 20,10$ & $56,92 \pm 16,10$ & $64,18 \pm 17,48$ & $67,79 \pm 39,64$ & $63,33 \pm 25,89$ & $54,98 \pm 19,43$ \\
\hline $31-40$ yaş aras1 & $73,51 \pm 20,77$ & $72,08 \pm 35,92$ & $64,79 \pm 20,38$ & $56,08 \pm 15,25$ & $64,72 \pm 15,21$ & $68,45 \pm 38,23$ & $62,31 \pm 25,52$ & $52,90 \pm 18,83$ \\
\hline 40 yaş üzeri & $66,47 \pm 21,52$ & $67,24 \pm 44,22$ & $63,80 \pm 18,62$ & $57,07 \pm 15,70$ & $64,55 \pm 16,13$ & $77,59 \pm 48,92$ & $62,50 \pm 26,60$ & $51,72 \pm 22,33$ \\
\hline$p$ değeri* & $<0,001$ & 0,694 & 0,751 & 0,836 & 0,948 & 0,249 & 0,925 & 0,434 \\
\hline \multicolumn{9}{|l|}{ Cinsiyet } \\
\hline Kadın & $73,59 \pm 19,91$ & $69,22 \pm 38,60$ & $62,50 \pm 20,09$ & $55,35 \pm 15,60$ & $63,81 \pm 39,95$ & $69,11 \pm 39,95$ & $61,33 \pm 25,59$ & $52,30 \pm 19,38$ \\
\hline Erkek & $83,69 \pm 17,90$ & $81,97 \pm 31,67$ & $73,60 \pm 16,73$ & $64,01 \pm 13,65$ & $68,65 \pm 16,47$ & $71,03 \pm 43,23$ & $71,51 \pm 25,32$ & $61,55 \pm 18,90$ \\
\hline$p$ değeri** & $<0,001$ & $<0,001$ & $<0,001$ & $<0,001$ & $<0,001$ & 0,746 & $<0,001$ & $<0,001$ \\
\hline \multicolumn{9}{|l|}{ Öğrenim durumu } \\
\hline Lise mezunu & $79,47 \pm 17,80$ & $66,00 \pm 18,30$ & $62,00 \pm 18,30$ & $53,93 \pm 17,37$ & $61,22 \pm 16,01$ & $61,78 \pm 41,62$ & $57,00 \pm 27,51$ & $51,67 \pm 18,40$ \\
\hline Lisans mezunu & $74,58 \pm 19,81$ & $72,80 \pm 37,31$ & $64,90 \pm 19,90$ & $57,82 \pm 14,59$ & $65,68 \pm 16,52$ & $72,64 \pm 40,33$ & $64,47 \pm 25,17$ & $54,97 \pm 19,78$ \\
\hline Yüksek lisans ve üzeri & $72,55 \pm 21,50$ & $69,69 \pm 36,63$ & $63,09 \pm 21,60$ & $54,94 \pm 16,82$ & $63,61 \pm 15,34$ & $65,95 \pm 38,80$ & $62,37 \pm 25,63$ & $51,11 \pm 19,63$ \\
\hline$p$ değeri* & 0,070 & 0,363 & 0,472 & 0,086 & 0,093 & 0,077 & 0,083 & 0,167 \\
\hline \multicolumn{9}{|l|}{ Medeni durum } \\
\hline Bekâr & $81,97 \pm 15,99$ & $79,31 \pm 34,78$ & $66,89 \pm 19,41$ & $59,55 \pm 15,20$ & $66,60 \pm 17,98$ & $73,10 \pm 38,14$ & $66,81 \pm 25,91$ & $58,62 \pm 19,59$ \\
\hline Evli & $71,57 \pm 20,80$ & $66,91 \pm 38,80$ & $62,62 \pm 20,19$ & $55,09 \pm 15,64$ & $63,44 \pm 15,25$ & $67,57 \pm 41,37$ & $60,78 \pm 25,50$ & $51,12 \pm 19,10$ \\
\hline$p$ değeri** & $<0,001$ & $<0,001$ & $<0,001$ & $<0,001$ & 0,071 & 0,176 & $<0,001$ & $<0,001$ \\
\hline
\end{tabular}

Bizim çalışmamızda ise bekâr hemşirelerin yaşam kalitesi daha yüksek düzeydedir. $\mathrm{Bu}$ farklılığın nedeni, hemşirelik mesleğine özgü diğer faktörler, çalışma yaşamındaki maddi kazancın bireysel kullanılabilmesi ya da evli hemşirelerin daha ileri yaşta olması nedeniyle, yaşın medeni durum ve yaşam kalitesi arasındaki ilişkide karıştırıcı bir faktör olarak yer alması olabilir.

Çalışmamızda BKİ ile FF alt boyutunda yaşam kalitesi arasında negatif yönlü bir ilişki saptadık. Bir diğer ifadeyle düşük kilolu hemşireler daha yüksek düzeyde FF yaşam kalitesine sahiptir. Bunun açıklaması olarak, kilo kaybının bireylerin fiziksel aktivitelerinde ve ağrı hislerinde düzelme sağlayarak yaşam kalitesini artırması olduğu söylenebilir. ${ }^{30}$
Kronik hastalıklarda hastalığın getirdiği kısıtlamalar ve tedavi sürecinin oluşturduğu kaygı, kişilerin fiziksel ve sosyal hayatlarını, dolayısıyla yaşam kalitelerini olumsuz etkilemektedir. Hemşireler ile yürütülen bir çalışmada, kronik hastalık varlığı ve sürekli ilaç kullanımının yaşam kalitesini azalttığ bildirilmiştir. ${ }^{31}$ Bunun bir açıklaması olarak, kronik hastalıklar kişilerin fiziksel aktivitelerini kısıtlayarak yaşam kalitesini azaltmaktadır., ${ }^{2,32}$

Fiziksel yönden aktif bireylerin bedensel görünüşlerini olumlu algılaması sonucunda, pozitif duygularla kendilerine olan güven hissi artmaktadır. Böylelikle anksiyete ve depresyon seviyesi azalarak uyku kalitesi artmaktadır. ${ }^{33,34}$ Fiziksel yönden aktif yaşamın, bireyi olumsuz alışkanlıklardan koruyup sosyalleştirmeyi arttırarak yaşam kalitesini yükseltebileceği bildirilmektedir. ${ }^{35}$ Ayrıca, başka meslek gruplarıyla 
yapılan çalışmalarda fiziksel aktivitenin yaşam kalitesini arttırdığı yönünde veriler elde edilmiştir. ${ }^{36,37}$

Çalışmanın kısıtlılıkları arasında en önemlisi, tek bir hastanede çalışan hemşireler ile yürütülmüş olmasıdır. $\mathrm{Bu}$ nedenle, çalışma sonuçlarını tüm hemşire popülâsyonuna genelleyemeyiz. Çalışmanın bir diğer kısıtlılığı, nöbet sıklığı, çalışılan birim gibi hemşirelerin çalışma yaşamına ilişkin değişkenlerin analize dâhil edilememiş olmasıdır. Çalışmanın en önemli güçlü yanı ise, fiziksel aktivitenin ve sosyo-demografik özelliklerin yaşam kalitesine etkisinin bir arada değerlendirilmiş olmasıdır. Çalışma sonuçları yorumlanırken kısıtlılık ve güçlü yanlar göz önünde bulundurulmalıdır.

Tablo 3. Katılımcıların bazı sağlık özelliklerine göre yaşam kalitesi düzeyleri.

\begin{tabular}{|c|c|c|c|c|c|c|c|c|}
\hline \multirow{2}{*}{ Özellik $(n=442)$} & \multicolumn{8}{|c|}{ SF-36 Yaşam Kalitesi Ölçeği Alt Boyut Puanları (Ortalama \pm SS) } \\
\hline & FF & FFRK & BA & GS & MS & EFRK & SF & $\mathbf{C} / \mathbf{E}$ \\
\hline \multicolumn{9}{|c|}{ Beden kitle indeksi } \\
\hline Zayif & $77,00 \pm 23,60$ & $85,00 \pm 57,98$ & $57,00 \pm 18,89$ & $52,00 \pm 16,53$ & $64,40 \pm 17,93$ & $80,00 \pm 45,00$ & $58,75 \pm 19,59$ & $52,00 \pm 17,82$ \\
\hline Normal kilolu & $76,31 \pm 19,40$ & $67,94 \pm 37,58$ & $63,13 \pm 19,81$ & $56,84 \pm 15,22$ & $64,59 \pm 16,52$ & $66,14 \pm 38,33$ & $62,60 \pm 25,37$ & $55,00 \pm 19,88$ \\
\hline Fazla kilolu & $75,00 \pm 19,60$ & $75,89 \pm 36,75$ & $67,53 \pm 19,21$ & $57,81 \pm 15,80$ & $64,05 \pm 16,13$ & $73,70 \pm 44,70$ & $62,94 \pm 26,98$ & $52,58 \pm 19,68$ \\
\hline Obez & $64,58 \pm 21,78$ & $69,29 \pm 37,41$ & $58,29 \pm 23,08$ & $50,58 \pm 16,67$ & $65,49 \pm 14,74$ & $72,39 \pm 33,80$ & $64,29 \pm 25,92$ & $47,85 \pm 16,29$ \\
\hline$p$ değeri* & $<0,001$ & 0,142 & $<0,001$ & 0,072 & 0,971 & 0,246 & 0,944 & 0,188 \\
\hline \multicolumn{9}{|c|}{ Kronik hastalık varlığ } \\
\hline Var & $67,32 \pm 18,60$ & $57,04 \pm 39,00$ & $53,80 \pm 22,58$ & $45,78 \pm 16,10$ & $62,30 \pm 16,48$ & $67,13 \pm 33,10$ & $58,80 \pm 25,91$ & $49,37 \pm 20,00$ \\
\hline Yok & $76,44 \pm 19,88$ & $73,65 \pm 37,20$ & $65,99 \pm 18,90$ & $58,61 \pm 14,69$ & $64,90 \pm 16,20$ & $69,81 \pm 41,65$ & $63,51 \pm 25,70$ & $54,40 \pm 19,40$ \\
\hline$p$ değeri** & $<0,001$ & $<0,001$ & $<0,001$ & $<0,001$ & 0,220 & 0,610 & 0,159 & $<0,001$ \\
\hline \multicolumn{9}{|c|}{ Sürekli ilaç kullanımı } \\
\hline Var & $64,78 \pm 19,81$ & $59,10 \pm 41,05$ & $53,30 \pm 20,70$ & $46,43 \pm 16,72$ & $61,58 \pm 16,31$ & $75,75 \pm 45,88$ & $59,65 \pm 26,20$ & $48,57 \pm 19,77$ \\
\hline Yok & $76,77 \pm 19,43$ & $73,08 \pm 37,03$ & $65,55 \pm 19,51$ & $58,32 \pm 14,75$ & $64,99 \pm 16,20$ & $68,27 \pm 39,30$ & $63,30 \pm 25,68$ & $54,47 \pm 19,41$ \\
\hline$p$ değeri** & $<0,001$ & $<0,001$ & $<0,001$ & $<0,001$ & 0,115 & 0,165 & 0,290 & $<0,001$ \\
\hline
\end{tabular}

Tablo 4. Katılımcıların fiziksel aktivite düzeylerine göre yaşam kalitesi düzeyleri.

\begin{tabular}{|c|c|c|c|c|c|c|c|c|}
\hline \multirow{2}{*}{ Özellik $(n=442)$} & \multicolumn{8}{|c|}{ SF-36 Yaşam Kalitesi Ölçeği Alt Boyut Puanları (Ortalama \pm SS) } \\
\hline & FF & FFRK & BA & GS & MS & EFRK & SF & $\mathbf{C} / \mathbf{E}$ \\
\hline \multicolumn{9}{|c|}{ Fiziksel aktivite düzeyi } \\
\hline Aktif olmayan & $67,40 \pm 21,21$ & $61,10 \pm 44,81$ & $61,40 \pm 19,27$ & $52,53 \pm 14,55$ & $61,67 \pm 16,22$ & $64,79 \pm 44,88$ & $57,49 \pm 25,04$ & $48,49 \pm 19,89$ \\
\hline Düşük düzey & $77,14 \pm 18,93$ & $73,70 \pm 34,61$ & $63,17 \pm 20,79$ & $55,97 \pm 16,07$ & $64,50 \pm 14,87$ & $69,50 \pm 37,88$ & $62,85 \pm 26,39$ & $53,51 \pm 18,27$ \\
\hline Yeterli düzey & $81,99 \pm 16,17$ & $80,40 \pm 29,48$ & $70,34 \pm 18,10$ & $64,43 \pm 13,35$ & $68,95 \pm 18,50$ & $76,51 \pm 37,88$ & $71,02 \pm 23,33$ & $61,99 \pm 19,35$ \\
\hline$p$ değeri* & $<0,001$ & $<0,001$ & $<0,001$ & $<0,001$ & $<0,001$ & 0,101 & $<0,001$ & $<0,001$ \\
\hline
\end{tabular}




\section{Sonuç}

Yaş, cinsiyet, kronik hastalık varlığ 1 gibi yaşam kalitesini olumsuz yönde etkileyen faktörlerin varlığına rağmen, yeterli düzeyde fiziksel aktivite hemşirelerin yaşam kalitesini olumlu şekilde etkilemektedir. Hemşirelerin gerek çalışma esnasında gerekse de çalıșma yaşamı dışında, yeterli düzeyde fiziksel aktivite olanaklarının bulunması ve bu yönde geliştirilecek müdahaleler hemşirelerin yaşam kalitesine dolayısıyla çalışma yaşamlarına olumlu katk1 sunabilecektir. Hastanelerin ya da sağlık merkezlerinin çalışan sağlığ birimlerince düzenlenecek hizmet için eğitim, işyerinde fiziksel aktivite olanaklarının (egzersiz yapilabilecek spor salonu ve egzersiz eğitmeni görevlendirilmesi gibi) yaratılması ve ilgili hastane yönetimlerinin bu olanakları idari yönden desteklemeleri çalışma yaşamında hemşirelere yönelik müdahale örnekleri olabilir. Çalışma yaşamı dışında ise hemşirelik dernekleri ve ilgili diğer sivil toplum kuruluşları benzer müdahaleler geliştirebilir. Hemşirelerin yaşam kalitesinin iyileştirilmesi, hastalara sunulan bakım kalitesini artırabilecektir. ${ }^{38}$

\section{Araştırmanın Etik Boyutu}

Araştırma için ilgili üniversitenin etik kurulundan etik kurul izni (Etik Kurul No: 2017-05, Tarih: 02/05/2017), ilgili ilin Kamu Hastaneleri Birliği Genel Sekreterliğinden idari izin alınmıştır. Çalışmaya katılmaya aday tüm hemşireler sözel olarak bilgilendirilmiş ve gönüllülük esasına göre katılmayı kabul edenlerden yazılı onam formu alınmıştır. Çalışma, tasarımından raporlama aşamasına kadar Helsinki Bildirgesi ilkelerine uygun olarak yürütülmüştür.

\section{Bilgilendirilmiş Onam}

Araştırmamıza katılan 442 hemşireye bilgilerinin gizli tutulacağı, herhangi bir ücret talep edilmeyeceği ve herhangi bir ücret ödenmeyeceği, tamamen gönüllülük esasına dayalı bir çalışma olduğu kendilerine anlatılarak onamları alınmıştır.

\section{Yazar Katkıları}

Araştırmanın hipotezi, sonuca ulaşabilmek için gerekli dizayn, bulguların mantıklı açıklanması ve sunumu F.K. ve N.T. tarafından oluşturulmuştur. Araştırmamız için gerekli verilerin toplanması ve çalışmamızın yazımı F.K. tarafından yapılmıştır.

\section{Teşekkür}

Araştırmamıza katılan tüm hemşirelerimize teşekkür ederiz.

\section{Çıkar Çatışması Beyanı}

Yazarlar arasında hiçbir çıkar çatışması bulunmamaktadir.

\section{Araştırma Desteği}

$\mathrm{Bu}$ çalışmanın hiçbir aşamasında hiçbir kişi, kurum ya da kuruluştan maddi destek alınmamıştır.

\section{Beyanlar}

Çalışmamız daha önce herhangi bir yerde sunulmamıştır.

\section{Kaynaklar}

1. Saint-Maurice PF, Troiano RP, Matthews CE, Kraus WE. Moderate-to-Vigorous Physical Activity and All-Cause Mortality: Do Bouts Matter? $J$ Am Heart Assoc. 2018;7(6):e007678.

2. Kruk J. Physical activity in the prevention of the most frequent chronic diseases: an analysis of the recent evidence. Asian Pac J Cancer Prev. 2007;8(3):325-338.

3. Global Recommendations on Physical Activity for Health. Geneva: World Health Organization; 2010.

4. Glinac A, Matovic L, Saric E, Bratovcic V, Sinanovic S. The Quality of Life in Chronic Patients in the Process of Rehabilitation. Mater Sociomed. 2017;29(3):168-171.

5. Recommendations to increase physical activity in communities. American journal of preventive medicine. 2002;22(4 Suppl):6772.

6. Breda J, Jakovljevic J, Rathmes G, et al. Promoting healthenhancing physical activity in Europe: Current state of surveillance, policy development and implementation. Health Policy. 2018;122(5):519-527.

7. Joseph G, Mogelvang R, Biering-Sørensen T, Nielsen G, Schnohr P, Sogaard P. The association between physical activity and cardiac performance is dependent on age: the Copenhagen City Heart Study. Int J Cardiovasc Imaging. 2019;35(7):1249-1258.

8. Jakicic JM, Davis KK. Obesity and physical activity. Psychiatr Clin North Am. 2011;34(4):829-840.

9. Writing Group M, Mozaffarian D, Benjamin EJ, et al. Heart Disease and Stroke Statistics-2016 Update: A Report From the American Heart Association. Circulation. 2016;133(4):e38e360.

10. Haskell WL, Lee IM, Pate RR, et al. Physical activity and public health: updated recommendation for adults from the American College of Sports Medicine and the American Heart Association. Med Sci Sports Exerc. 2007;39(8):1423-1434.

11. Post MWM. Definitions of quality of life: what has happened and how to move on. Top Spinal Cord Inj Rehabil. 2014;20(3):167-180.

12. Cruz LN, Fleck MPdA, Oliveira MR, et al. Health-related quality of life in Brazil: normative data for the SF-36 in a general population sample in the south of the country. Cien Saude Colet. 2013;18(7):1911-1921.

13. Osarrodi A, Golafshani A, Akaberi S. Relationship between spiritual well-being and quality of life in nurses. Journal of North Khorasan University of Medical Sciences. 2012;3(4):7988. 
14. Joslin LE, Davis CR, Dolan P, Clark EM. Quality of life and neck pain in nurses. Int $J$ Occup Med Environ Health. 2014;27(2):236-242.

15. von Elm E, Altman DG, Egger M, et al. The Strengthening the Reporting of Observational Studies in Epidemiology (STROBE) Statement: Guidelines for Reporting Observational Studies. 2007;18(6):800-804.

16. Executive summary of the clinical guidelines on the identification, evaluation, and treatment of overweight and obesity in adults. Archives of internal medicine. 1998;158(17):1855-1867.

17. Craig CL, Marshall AL, Sjöström M, et al. International physical activity questionnaire: 12-country reliability and validity. Med Sci Sports Exerc. 2003;35(8):1381-1395.

18. Öztürk M. Üniversitede eğitim-öğretim gören öğrencilerde Uluslararası Fiziksel Aktivite Anketinin geçerliliği ve güvenirliği ve fiziksel aktivite düzeylerinin belirlenmesi [Yüksek Lisans Tezi]. Ankara: Fizik Tedavi ve Rehabilitasyon Programı, Hacettepe Üniversitesi Sağlık Bilimleri Enstitüsü; 2005 .

19. Ware JE, Jr., Sherbourne CD. The MOS 36-item short-form health survey (SF-36). I. Conceptual framework and item selection. Med Care. 1992;30(6):473-483.

20. Koçyiğit H, Aydemir O, Fişek G, Ölmez N, Memiș A. Kısa Form-36 (SF-36)'nın Türkçe Versiyonunun Güvenilirliği ve Geçerliliği. Reliability and Validity of the Turkish Version of Short Form-36 (SF-36). Ilaç ve Tedavi Dergisi. 1999;12:102106.

21. Genc A, Sener U, Yalcinkaya H, Üçok K. Kadın ve Erkek Genç Erişkinler Arasında Fiziksel Aktivite ve Yaşam Kalitesi Farklılıklarının Araștırılması [Investigation of Physical Activity and Quality of Life Differences between Male and Female Young Adults]. Kocatepe Tip Dergisi (Kocatepe Medical Journal). 2011;12:145-150.

22. Chappel SE, Verswijveren SJJM, Aisbett B, Considine J, Ridgers ND. Nurses' occupational physical activity levels: A systematic review. Int J Nurs Stud. 2017;73:52-62.

23. Gholami A, Farsi M, Hashemi Z, Lotfabadi P. Quality of Life in Nurses Working in Neyshabur Hospitals. Thrita Journal of Medical Sciences. 2012;1:94-100.

24. Silva AA, Souza JMPd, Borges FNdS, Fischer FM. Healthrelated quality of life and working conditions among nursing providers. Revista de Saúde Pública. 2010;44:718-725.

25. Kızılırmak M, Demir S. Hastanede çalışan hemşirelerde depresyon ve yaşam kalitesinin incelenmesi. TAF Preventive Medicine Bulletin. 2016;15(2):132-140.

26. Farrokhian AR, Motaghi M, Sharif M. Quality of Life in Nurses; Case Study of Shahid Beheshti Hospital of Kashan City, Iran. International Archives of Health Sciences. 2016;3:93-99.

27. Hajian-Tilaki K, Heidari B, Hajian-Tilaki A. Are Gender Differences in Health-related Quality of Life Attributable to Sociodemographic Characteristics and Chronic Disease Conditions in Elderly People? Int J Prev Med. 2017;8:95-95.

28. Fodor E, Lane L, Schippers J, van der Lippe T. Gender Differences in Quality of Life. In: Bäck-Wiklund M, van der Lippe T, den Dulk L, Doorne-Huiskes A, eds. Quality of Life and Work in Europe: Theory, Practice and Policy. London: Palgrave Macmillan UK; 2011:149-161.

29. Aydıner Boylu A, Paçacioğlu B. Yaşam kalitesi ve göstergeleri. Akademik Araştırmalar ve Çalışmalar Dergisi (AKAD). 2016:137-150.

30. Fine JT, Colditz GA, Coakley EH, et al. A prospective study of weight change and health-related quality of life in women. JAMA. 1999;282(22):2136-2142.

31. Say Şahin D, Önal Ö, Kılınç AS. Acil Servis ve Yoğun Bakım Hemşirelerinin Yaşam Kalitesinin Değerlendirilmesi. Mehmet Akif Ersoy Üniversitesi Sağlık Bilimleri Enstitüsü Dergisi. 2014;2(2):81-92.

32. Della Valle E, Grimaldi R, Farinaro E. Importance of physical activity for prevention of chronic diseases. Ann Ig. 2008;20(5):485-493.

33. Gill DL, Hammond CC, Reifsteck EJ, et al. Physical activity and quality of life. J Prev Med Public Health. 2013;46 Suppl 1(Suppl 1):S28-S34.

34. Jamali A, Tofangchiha S, Jamali R, et al. Medical students' health-related quality of life: roles of social and behavioural factors. Med Educ. 2013;47(10):1001-1012.
35. Vankim NA, Nelson TF. Vigorous physical activity, mental health, perceived stress, and socializing among college students. Am J Health Promot. 2013;28(1):7-15.

36. Campos ACV, e Ferreira EF, Vargas AMD, Albala C. Aging, Gender and Quality of Life (AGEQOL) study: factors associated with good quality of life in older Brazilian community-dwelling adults. Health and Quality of Life Outcomes. 2014;12(1):166.

37. Vagetti GC, Barbosa Filho VC, Moreira NB, Oliveira Vd, Mazzardo O, Campos Wd. Association between physical activity and quality of life in the elderly: a systematic review, 2000-2012. Braz J Psychiatry. 2014;36(1):76-88.

38. Makabe S, Kowitlawakul Y, Nurumal MS, et al. Investigation of the key determinants of Asian nurses' quality of life. Ind Health. 2018;56(3):212-219. 